University of Nebraska - Lincoln

DigitalCommons@University of Nebraska - Lincoln

USDA National Wildlife Research Center - Staff Publications
U.S. Department of Agriculture: Animal and Plant Health Inspection Service

2012

\title{
Genetic structure of a Virginia opossum (Didelphis virginiana) population inhabiting a fragmented agricultural ecosystem
}

\author{
William S. Beatty \\ Purdue University, wsbeatty@purdue.edu \\ James C. Beasley \\ Purdue University, beasley@srel.uga.edu \\ Guha Dharmarajan \\ National Institute of Allergy and Infectious Diseases, guha@iiserkol.ac.in \\ Olin E. Rhodes Jr. \\ University of Georgia's Savannah River Ecology Lab, rhodes@srel.uga.edu
}

Follow this and additional works at: https://digitalcommons.unl.edu/icwdm_usdanwrc

Part of the Life Sciences Commons

Beatty, William S.; Beasley, James C.; Dharmarajan, Guha; and Rhodes, Olin E. Jr., "Genetic structure of a Virginia opossum (Didelphis virginiana) population inhabiting a fragmented agricultural ecosystem" (2012). USDA National Wildlife Research Center - Staff Publications. 1097.

https://digitalcommons.unl.edu/icwdm_usdanwrc/1097

This Article is brought to you for free and open access by the U.S. Department of Agriculture: Animal and Plant Health Inspection Service at DigitalCommons@University of Nebraska - Lincoln. It has been accepted for inclusion in USDA National Wildlife Research Center - Staff Publications by an authorized administrator of DigitalCommons@University of Nebraska - Lincoln. 


\title{
Genetic structure of a Virginia opossum (Didelphis virginiana) population inhabiting a fragmented agricultural ecosystem
}

\author{
William S. Beatty, James C. Beasley, Guha Dharmarajan, and Olin E. Rhodes, Jr.
}

\begin{abstract}
Fragmentation has drastically altered the quality of habitats throughout numerous ecosystems, often leading to dramatic changes in the composition of wildlife communities. The ecology and associated movement behavior of a species may also be modified as a result of forest fragmentation, resulting in changes in genetic composition of the affected species. In this research, we evaluated the genetic structure of the Virginia opossum (Didelphis virginiana Kerr, 1792) at the landscape and local scales in a fragmented, agricultural ecosystem in northern Indiana using 13 microsatellite loci. We examined 290 samples from opossums inhabiting 28 discrete habitat patches, and evaluated partitioning of genetic variation of opossums among and within habitat patches. We observed low but significant levels of genetic structure $\left(F_{\mathrm{ST}}=0.005\right)$ overall, and pairwise comparisons of $F_{\mathrm{ST}}$ values among habitat patches also were relatively low. Relatedness within patches was highly variable $\left(-0.077 \leq r_{x y} \leq 0.060\right)$, with a few patches exhibiting significantly higher levels of relatedness than random expectations, and we detected no evidence of sex-biased natal dispersal. These results contrast with previous field studies that documented male-biased dispersal in the Virginia opossum, indicating dispersal in this species is plastic and dependent upon local environmental conditions.

Résumé : La fragmentation a fortement modifié la qualité des habitats dans un grand nombre d'écosystèmes, ce qui a souvent causé des changements spectaculaires dans la composition des communautés de la faune sauvage. L'écologie et le comportement de déplacement associé d'une espèce peuvent aussi être changés à cause de la fragmentation des forêts, ce qui entraîne une altération dans la composition génétique de l'espèce affectée. Notre étude évalue à l'analyse de 13 locus microsatellites la structure génétique des sarigues de Virginie (Didelphis virginiana Kerr, 1792) aux échelles du paysage et de la localité dans un écosystème agricole fragmenté dans le nord de l'Indiana. Nous avons examiné 290 échantillons de sarigues habitant 28 taches séparées d'habitat et mesuré la partition de la variation génétique des sarigues entre les taches d'habitat et à l'intérieur de ces taches. Il existe des niveaux faibles, mais significatifs, de structure génétique $\left(F_{\mathrm{ST}}=0,005\right)$ dans l'ensemble; les comparaisons deux par deux des valeurs de $F_{\mathrm{ST}}$ dans les taches d'habitat sont aussi relativement faibles. Le degré de parenté à l'intérieur des taches est très variable $\left(-0,077 \leq r_{x y} \leq 0,060\right)$, mais quelques taches affichent des degrés de parenté significativement supérieurs à ce qu'on attend par chance; il n'y a pas d'indication de dispersion à la naissance particulière selon le sexe. Ces résultats sont bien différents de ceux d'études de terrain antérieures qui décrivent une dispersion qui favorise les sarigues de Virginie mâles, ce qui montre que la dispersion est variable chez cette espèce et dépend des conditions locales de l'environnement.
\end{abstract}

[Traduit par la Rédaction]

\section{Introduction}

Fragmentation attributed to increasing row crop agriculture in the central United States has produced ecosystems characterized by numerous small, isolated forest patches exhibiting a reduced capacity to support biological diversity (Ebinger 1997). Possible genetic consequences of habitat fragmentation to wildlife involve increased genetic drift owing to small population sizes and reduced gene flow among habitat patches. Indeed, the majority of studies that have examined genetic diversity within fragmented ecosystems have reported reduced genetic variation within remnant subpopulations (genetic drift) and increased genetic variation among subpopulations (see Keyghobadi 2007). However, relatively few such studies have examined the genetic effects of fragmentation on mesopredators (but see Dallas et al. 2002; Dharmarajan et al. 2009; Sacks et al. 2010).

The Virginia opossum (Didelphis virginiana Kerr, 1792) is the lone marsupial native to the United States and has gradually expanded its range northward since European settlement (Gardner and Sunquist 2003). Several factors are likely con-

Received 23 June 2011. Accepted 22 October 2011. Published at www.nrcresearchpress.com/cjz on 5 January 2012.

W.S. Beatty, J.C. Beasley, G. Dharmarajan,* and O.E. Rhodes, Jr. ${ }^{\dagger}$ Department of Forestry and Natural Resources, Purdue University, 195 Marsteller Street, West Lafayette, IN 47907, USA.

Corresponding Author: William Beatty (e-mail: wsbeatty@purdue.edu).

*Present address: Laboratory of Malaria and Vector Research, National Institute of Allergy and Infectious Diseases, National Institutes of Health, 12735 Twinbrook Parkway, Rockville, MD 20852, USA.

${ }^{\dagger}$ Present address: National Wildlife Research Center, 4101 LaPorte Avenue, Fort Collins, CO 80521, USA. 
tributing to the range expansion of this species, including its adaptability to variable habitats (McManus 1974), the geographic expansion of anthropogenic resources (Kanda et al. 2006), and the extirpation of large carnivores in the central United States (Crooks and Soule 1999). Additionally, the opossum is considered a generalist mesopredator that is capable of consuming nearly any food that is available, including carrion, garbage, and earthworms (Whitaker and Mumford 2009). Consequently, it is often perceived as a species that possesses a high tolerance for disturbance. In fact, there is empirical evidence that opossums are tolerant of habitat fragmentation associated with human-dominated landscapes (Crooks 2002; Gehring and Swihart 2003), although these studies did not examine fine-scale population organization in this species.

Resources in fragmented, agricultural ecosystems are both spatially (Moore and Swihart 2005) and temporally variable (Beasley et al. 2007), thus providing an environment that is conducive to the development of local genetic structure at fine spatial scales. For example, the raccoon (Procyon lotor (L., 1758)), the primary competitor of the Virginia opossum, exhibits significant levels of local genetic structure as a result of the spatial aggregation of closely related individuals in an agriculturally dominated area in Indiana (Dharmarajan et al. 2009). In contrast, movement behavior in Virginia opossums has been documented to be nomadic (McManus 1974; Whitaker and Mumford 2009), but male-biased dispersal with female philopatry has also been observed (Fitch and Sandidge 1953; Holmes and Sanderson 1965; Wright 1989; Ryser 1995).

Population genetic tools are being increasingly employed to elucidate ecological and behavioral patterns of wildlife species (DeWoody et al. 2010). Although opossums have been studied extensively both historically and recently using traditional techniques, such as radiotelemetry and capturemark-recapture (Fitch and Sandidge 1953; Gipson and Kamler 2001), population organization of the species has not been thoroughly evaluated with the aid of molecular markers. In genetic analyses, there is a continuum of possible outcomes that may be observed given the range of movement behaviors that could exist in the Virginia opossum. For example, nomadic movement behavior would produce no observable patterns of local or landscape-level genetic structure, and our study area would essentially constitute one panmictic population. In contrast, local populations could be genetically distinct units owing to the spatial aggregation of related individuals (Dharmarajan et al. 2009), producing a pattern of local genetic structure with high levels of relatedness among resident females and low levels of relatedness among resident males within local populations.

In this study, we utilize a highly polymorphic panel of microsatellites (Fike et al. 2009) to elucidate patterns of landscape and local genetic structure in Virginia opossums inhabiting a fragmented, agricultural ecosystem. To achieve this goal, our objectives were $(i)$ to quantify partitioning of genetic variation within and among opossums inhabiting spatially discrete habitat patches referred to as local populations; (ii) to evaluate levels of social structure in local populations, including relatedness among resident individuals; (iii) to identify the presence of sex-biased dispersal among local populations; and $(i v)$ to evaluate landscape-level patterns of genetic structure to reveal geographic barriers to dispersal.

\section{Materials and methods}

\section{Study area}

Our study area was located within the Upper Wabash River Basin (UWB) in north-central Indiana and included $1165 \mathrm{~km}^{2}$ of primarily flat terrain within portions of Grant, Huntington, Miami, and Wabash counties. The mean elevation was $243 \mathrm{~m}$ above sea level, and topography was typically restricted to areas adjacent to drainage networks (Beasley et al. 2010). Agriculture accounted for $66 \%$ of the land use within the study area, while $14 \%$ of the total area was forested. Corn and soybeans dominated agricultural land use within the UWB, while hay, wheat, and other grains were rare. Forested areas were dominated by oak-hickory-maple (Quercus L. - Carya Nutt. - Acer L.) communities and were highly fragmented, with $72 \%$ of forest patches $<5$ ha and $<1 \%$ of patches $>100$ ha. Large contiguous forest tracts in the UWB were restricted to areas unsuitable for cultivation owing to frequent flooding or steep topography.

\section{Sample collection and laboratory methods}

Virginia opossums were trapped each spring (March-June) over a 2-year period (2007-2008) in 28 forest patches distributed throughout the study area. Patch and local population numbers follow Dharmarajan et al. (2009). The mean $( \pm \mathrm{SE})$ pairwise distance among sampled forest patches was $15.8 \pm$ $1.6 \mathrm{~km}$, with approximately $88 \%$ of pairwise distances exceeding $6 \mathrm{~km}$ (supplementary Table S1). ${ }^{1}$ Trapping methods were described in detail in Beasley et al. (2011). Briefly, Tomahawk live traps (Tomahawk Live Trap Co., Tomahawk, Wisconsin, USA) baited with commercial cat food were placed in a grid (50 m spacing) within each forest patch and maintained for 10 consecutive nights. Captured opossums were ear-tagged (Monel \#3; National Band and Tag Company, Newport, Kentucky, USA), sexed, weighed, and a tissue sample (ear punch) was taken for genetic analysis prior to their release. Tissue samples were preserved in $100 \%$ ethanol and transferred to an ultra-low freezer for long-term storage. At the time of sampling, young of the year were present within the marsupium of parous females and were not traveling independently. Thus, young of the year were excluded from this research and all samples were breeding adults. Trapping and handling methods conformed to Purdue University Animal Care and Use Committee policies under Protocol 01-079.

Genomic DNA was extracted from ear tissue using a modified ammonium acetate protocol (Latch et al. 2008). Thirteen microsatellite loci were amplified via five multiplex polymerase chain reactions (PCR) based on methods outlined in Fike et al. (2009). Quality-control measures included two sets of allelic standards, a positive control, and negative control for each 96-well plate. Additionally, error rates for each locus

\footnotetext{
${ }^{1}$ Supplementary Tables S1 and S2 are available with the article through the journal Web site (http://nrcresearchpress.com/doi/suppl/10.1139/
} z11-119). 
Table 1. The number genotyped $(n)$, the number of alleles $(A)$, allelic richness $\left(A_{\mathrm{R}}\right)$, expected heterozygosity $\left(H_{\mathrm{E}}\right)$, observed heterozygosity $\left(H_{\mathrm{O}}\right)$, estimated $F_{\mathrm{IS}}$ values, and associated $p$ values for the $F_{\text {IS }}$ values $(p)$ for 290 Virginia opossum (Didelphis virginiana) samples from 28 habitat patches in northern Indiana.

\begin{tabular}{llrrllrl}
\hline Locus & $n$ & \multicolumn{1}{c}{$A$} & \multicolumn{1}{c}{$A_{\mathrm{R}}$} & $H_{\mathrm{E}}$ & $H_{\mathrm{O}}$ & \multicolumn{1}{c}{$F_{\mathrm{IS}}$} & \multicolumn{1}{l}{$p$} \\
\hline OP03 & 289 & 8.00 & 8.00 & 0.59 & 0.56 & 0.048 & 0.086 \\
OP08 & 290 & 7.00 & 6.99 & 0.73 & 0.72 & 0.018 & 0.316 \\
OP14 & 290 & 14.00 & 13.99 & 0.88 & 0.90 & -0.032 & 0.943 \\
OP16 & 290 & 7.00 & 7.00 & 0.73 & 0.73 & 0.010 & 0.397 \\
OP18 & 290 & 14.00 & 13.99 & 0.87 & 0.87 & -0.005 & 0.606 \\
OP19 & 290 & 11.00 & 11.00 & 0.84 & 0.84 & 0.000 & 0.527 \\
OP36 & 290 & 16.00 & 16.00 & 0.90 & 0.91 & -0.017 & 0.833 \\
OP38 & 287 & 8.00 & 8.00 & 0.82 & 0.73 & 0.108 & $<0.001^{*}$ \\
OP39 & 289 & 10.00 & 9.99 & 0.81 & 0.80 & 0.012 & 0.343 \\
OP41 & 289 & 15.00 & 14.99 & 0.86 & 0.80 & 0.077 & $0.001^{*}$ \\
OP42 & 290 & 10.00 & 9.99 & 0.81 & 0.78 & 0.034 & 0.128 \\
OP46 & 290 & 9.00 & 8.99 & 0.75 & 0.73 & 0.020 & 0.276 \\
OP48 & 289 & 8.00 & 7.99 & 0.81 & 0.81 & -0.001 & 0.531 \\
Mean & 289.46 & 10.54 & 10.53 & 0.80 & 0.78 & 0.020 & $0.003 *$ \\
\hline
\end{tabular}

Note: The $p$ values are the result of a one-tailed test in the direction of heterozygote deficit and were evaluated with the false discovery rate (experiment-wide alpha $\left(\alpha_{\mathrm{EW}}\right)$ of 0.015). An asterisk denotes a significant value.

were quantified via blind scoring of previously typed individuals.

\section{Basic statistics}

We considered all animals trapped in a patch to represent a local population owing to the highly fragmented nature of the study area, while the entire set of pooled samples were considered the global population. To determine if combining individuals from different years into a global population was appropriate for subsequent analyses, we implemented an analysis of molecular variance (AMOVA) in the program ARLEQUIN version 2.0 (Schneider et al. 2000). In this hierarchical analysis, we denoted all individuals from 2007 as one population, while all individuals from 2008 represented the second population, and partitioned genetic variation into components at the intrapopulation and interpopulation levels. Based on the AMOVA, we detected no evidence that genetic variance was partitioned significantly between years $\left(F_{\mathrm{ST}}<\right.$ $0.001, p=0.708$ ), and thus, we pooled both years for all subsequent analyses.

We calculated allelic richness for the global population in FSTAT (Goudet 1995; Goudet 2002), and observed and expected heterozygosities were calculated with the program GDA (Lewis and Zaykin 2001). We calculated Weir and Cockerham's (1984) estimate of $F_{\text {IS }}$ for the global population and within each local population, and tested for significant deviations from Hardy-Weinberg equilibrium (HWE) at both these scales using the randomization procedure (10000 randomizations) implemented in FSTAT. We controlled for type I error with the false discovery rate (FDR) of Benjamini and Yekutieli (2001). This method obtains an experiment-wide alpha level $\left(\alpha_{\mathrm{EW}}\right)$ based on the number of comparisons and controls for dependency among tests (Benjamini and Yekutieli 2001). The FDR is less conservative than the Bonferroni correction and offers increased statistical power as the number of comparisons increases (Narum 2006).

\section{Local genetic structure}

We estimated Weir and Cockerham's (1984) estimate of $F_{\mathrm{ST}}(\theta)$ among all local populations and among all pairwise combinations of local populations. To evaluate statistical significance of $F_{\mathrm{ST}}$ values, we implemented a randomization procedure in FSTAT. Specifically, we compared each observed $F_{\mathrm{ST}}$ value to a null distribution of 1000 values calculated via randomization of genotypes among local populations (Goudet et al. 1996). In a subsequent analysis, we repeated the analyses of $F$ statistics outlined above while using only those local populations with $n \geq 10$ individuals to minimize bias owing to low sample size. Because of the high number of pairwise comparisons, the type I error rate was controlled using the FDR.

\section{Social structure}

To evaluate the presence of significant levels of social structure within local populations of opossums, we calculated Queller and Goodnight's (1989) measure of relatedness $\left(r_{x y}\right)$ with $95 \%$ bootstrapped confidence intervals. We evaluated the significance of observed values of relatedness within local populations via comparison to a null distribution of 10 $000 r_{x y}$ values based on randomization of individuals among all local populations in GENALEX (Peakall and Smouse 2006). We used Queller and Goodnight's (1989) estimator of relatedness because it has been shown to exhibit a smaller variance when relatedness between individuals is high $(\geq 0.5)$ than have other estimators, and thus, is more conservative in regard to the identification of biologically significant relationships (Csilléry et al. 2006).

We also examined the relationship between spatial distance and relatedness values. To delineate biologically relevant distance classes, we consulted the literature for studies examining opossum home ranges that met the following criteria: (i) opossum movement was monitored via radiotelemetry and (ii) minimum convex polygon or kernel estimation was used to calculate home-range sizes. After evaluating data 
Table 2. The total number of individuals sampled ( $n)$, estimates of $F_{\text {IS }}$, and the Queller and Goodnight (1989) relatedness estimates for each local population $\left(r_{x y}\right)$ in a sample of 290 Virginia opossums (Didelphis virginiana) from northern Indiana.

\begin{tabular}{lrrr}
\hline Local & & & \\
population & $n$ & \multicolumn{1}{c}{$F_{\text {IS }}$} & \multicolumn{1}{c}{$r_{x y}$} \\
\hline 1 & 4 & 0.090 & 0.031 \\
3 & 3 & -0.015 & -0.077 \\
6 & 14 & -0.016 & -0.006 \\
7 & 15 & 0.061 & 0.005 \\
8 & 20 & 0.030 & 0.001 \\
9 & 15 & -0.017 & -0.003 \\
10 & 13 & -0.007 & 0.036 \\
11 & 14 & 0.013 & 0.017 \\
$12 \mathrm{a}$ & 5 & 0.042 & 0.043 \\
$12 \mathrm{~b}$ & 5 & -0.014 & -0.009 \\
13 & 8 & -0.008 & 0.000 \\
17 & 6 & 0.054 & -0.047 \\
18 & 9 & 0.083 & -0.028 \\
19 & 10 & 0.020 & 0.010 \\
20 & 9 & 0.070 & 0.002 \\
21 & 6 & -0.080 & 0.047 \\
22 & 6 & 0.035 & -0.011 \\
23 & 13 & 0.024 & -0.013 \\
24 & 9 & 0.013 & 0.002 \\
25 & 13 & -0.057 & $0.056^{*}$ \\
27 & 5 & -0.028 & -0.060 \\
29 & 13 & -0.031 & $0.060^{*}$ \\
30 & 8 & 0.043 & 0.025 \\
31 & 8 & 0.086 & -0.040 \\
32 & 13 & -0.012 & 0.014 \\
33 & 20 & 0.047 & 0.002 \\
34 & -0.001 & 0.001 \\
35 & 19 & 0.019 & -0.007 \\
\hline & & & \\
& 5 & &
\end{tabular}

Note: The false discovery rate was used to evaluate $r_{x y}$ estimates and an asterisk indicates a significant value (experiment-wide alpha $\left(\alpha_{\mathrm{EW}}\right)$ of 0.015$)$.

from the three studies that met these criteria (Gillette 1980; Allen et al. 1985; Gipson and Kamler 2001), we calculated the mean estimate of home-range size over the three aforementioned studies (67 ha) to estimate the linear dimension of a opossum home range as $818.54 \mathrm{~m}$. Based on a formula in Bowman et al. (2002), where median natal dispersal distance is equal to $7 \times$ (the linear dimension of home range), we calculated the median dispersal distance of opossums to be approximately $5.7 \mathrm{~km}$. Thus, we utilized $6 \mathrm{~km}$ intervals to delineate seven distance classes proceeding from the local population level (interval 1) and extending out to $30 \mathrm{~km}$, with all individuals $>30 \mathrm{~km}$ grouped into the final distance interval. We then used spatial autocorrelation analysis as implemented in the program SPAGeDi (Hardy and Vekemans 2002) to compare mean pairwise relatedness in local opossum populations relative to mean pairwise relatedness within our $6 \mathrm{~km}$ distance intervals.

\section{Sex-biased dispersal}

We evaluated the data for evidence of male-biased natal dispersal within our study area using four approaches. First, we calculated mean relatedness values and $95 \%$ bootstrapped confidence intervals $\left(r_{x y}\right.$; Queller and Goodnight 1989) within local populations separately for each sex using the program GENALEX. In this analysis, the more philopatric sex would exhibit significantly higher mean levels of relatedness within local populations than the dispersing sex.

In our second analysis, we calculated the mean corrected assignment index (mAIc) for each sex to determine the probability that an individual's genotype may occur in each local population given the allele frequencies in that population (Goudet 2002). We expected females, as the more philopatric sex (Ryser 1995), to have a higher probability of assignment to the local population from which they were originally sampled than males. To test for a significant difference in the sex-specific mAIc values, we compared the observed difference between the two sexes to a null distribution of 10000 values based on randomization of sex among individuals within local populations in FSTAT. We also examined the sex-specific variance in mAIc values (vAIc; Favre et al. 1997) as a third measure of sex-biased natal dispersal. In this analysis, we expected the vAIc would be greater for the dispersing sex (i.e., males) than the philopatric sex. To test for significant differences in vAIc values between the sexes, we compared the ratio of our observed vAIc values for males and females to a null distribution of 10000 values based on randomization of sex among individuals within local populations in FSTAT. Finally, we calculated $F_{\mathrm{ST}}$ values within local populations separately for both males and females. In this analysis, the more philopatric sex would have a more heterogeneous allelic distribution, and thus, a larger $F_{\mathrm{ST}}$ than the dispersing sex. To test for a significant difference between the $F_{\mathrm{ST}}$ values for males and females, we compared the observed difference between the values to a null distribution of 10000 values based on randomization of sex while maintaining genotypes within local populations in FSTAT.

\section{Landscape-level genetic structure}

We evaluated our data for patterns of genetic variation at the landscape scale using the program STRUCTURE version 2.2 (Pritchard et al. 2000). STRUCTURE is used to evaluate the probability of the observed data given a user-defined number of clusters (i.e., populations), the parameter $K$. A burnin of 50000 followed by 100000 iterations of the Markov chain Monte Carlo (MCMC) for $K=1$ to $K=10$ was performed 10 times for each value of $K$. We utilized the parameter $\Delta K$ (Evanno et al. 2005) to indicate the most likely number of populations within the data. The program GENELAND (Guillot et al. 2005b) also implements a MCMC algorithm to infer genetic structure, but additionally takes into account the spatial location of each data point. Thus, we also used GENELAND to infer the number of opossum populations in our data set. We performed 10 independent runs of the MCMC algorithm in GENELAND, wherein the Dirichlet model was used to simulate allele frequencies, the maximum rate of the Poisson process was set to 290, and the maximum number of nuclei was set to 870 based on the recommendations of Guillot et al. (2005a). For each independent run of the program, we applied an uncertainty coordinate of $1 \mathrm{~km}$ and 20000 iterations of the MCMC (200000+ thinning of 10 ) were used to infer the number of populations. We initially included all 28 local populations for both the STRUCTURE 
Fig. 1. Spatial autocorrelation analysis in a sample of 290 Virginia opossums (Didelphis virginiana) from a fragmented agricultural ecosystem in northern Indiana. Distance class 1 corresponds to within patch relatedness, while distance class 2 corresponds to relatedness among pairs of individuals that are between 1 and $6 \mathrm{~km}$ apart.

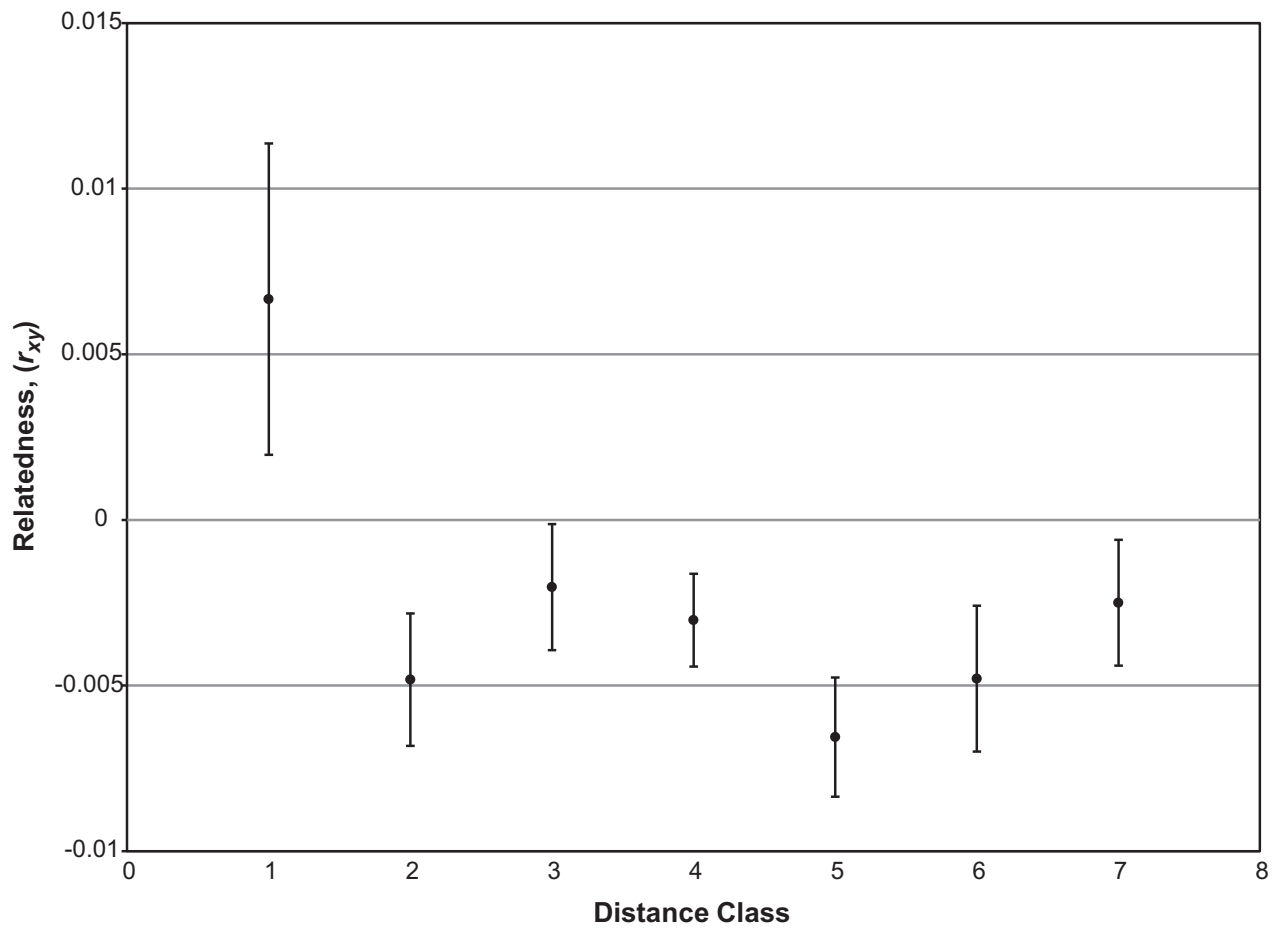

and the GENELAND analyses, but repeated the procedures with only local populations with $n \geq 10$ individuals to minimize bias owing to low sample size within local populations.

Finally, we evaluated our data set for evidence of isolation by distance (IBD), which is expected to produce a pattern in which geographically close individuals are more similar genetically than geographically distant individuals. We performed a Mantel test (Mantel 1967) in the program ALLELES IN SPACE (Miller 2005) to test for IBD and evaluated significance of the observed data using 10000 permutations of the data. Our Mantel test used pairwise matrices to evaluate correlations between geographic (Euclidean distance; m) and genetic ( $D_{i j}$; Nei et al. 1983; Miller 2005) distances among local populations.

\section{Results}

\section{Basic statistics}

We observed high levels of genetic diversity in the sample of 290 Virginia opossums collected over a 2-year period from northern Indiana with a mean of 10.54 alleles/locus, and overall mean expected and observed heterozygosities of 0.80 and 0.78 , respectively (Table 1 ). Missing genotypes accounted for $0.11 \%$ of the data and error rates were $<1.0 \%$. However, locus OP38 contained the highest rate of missing data $(0.69 \%)$ among all loci, indicating the possible presence of null alleles, albeit at small frequencies. Estimates of $F_{\text {IS }}$ for the global population revealed that 2 of the 13 loci utilized in this study exhibited a significant deficit of heterozygotes after correction for multiple comparisons (Table 1). No local populations deviated significantly from HardyWeinberg expectations after correction for multiple comparisons (Table 2).

\section{Local genetic structure}

Overall, we observed low but significant levels of population differentiation $\left(F_{\mathrm{ST}}=0.005, p<0.001\right)$ among local populations of opossums. An analysis that excluded locus OP38 revealed a similar pattern $\left(F_{\mathrm{ST}}=0.004 ; 95 \%\right.$ CI: -0.001 to 0.010$)$; thus all subsequent analyses included this locus. Pairwise comparisons of $F_{\mathrm{ST}}$ values among all local populations revealed a high variance in the extent of genetic differentiation exhibited among local population pairs $\left(-0.036 \leq F_{\mathrm{ST}} \leq 0.054\right)$. Approximately $5 \%$ of pairwise comparisons (19 of 378) were significant, largely attributed to local population 29 which exhibited evidence of significant genetic differentiation from 14 other local populations (supplementary Table S1). ${ }^{1}$

Our analyses including only local populations with $n \geq 10$ individuals (13 of 28) revealed slightly more evidence of genetic variance partitioning $\left(F_{\mathrm{ST}}=0.007, p<0.001 ; 95 \% \mathrm{CI}\right.$ : 0.002 to 0.012 ) than the analysis that included all local populations. Pairwise comparisons of $F_{\mathrm{ST}}$ values among these 13 local populations varied widely $\left(-0.005 \leq F_{\mathrm{ST}} \leq 0.031\right)$, and approximately $15 \%$ of pairwise comparisons of local patches (12 of 78) exhibited evidence of significant genetic differentiation. Again, pairwise variation among local populations was largely attributed to local population 29 , which exhibited evidence of significant genetic differentiation from 10 other local populations (supplementary Table S2). ${ }^{1}$

\section{Social structure}

We observed highly variable estimates of mean relatedness within local populations (range of $-0.077 \leq r_{x y} \leq 0.060$; mean $=0.002$ ) and approximately $7 \%$ of local populations (2 of 28) exhibited higher levels of relatedness than expected 
Table 3. The sample size $(n)$ and the Queller and Goodnight (1989) mean estimate of relatedness for both males and females in each local Virginia opossum (Didelphis virginiana) population in northern Indiana.

\begin{tabular}{|c|c|c|c|c|}
\hline \multirow{2}{*}{$\begin{array}{l}\text { Local } \\
\text { population }\end{array}$} & \multicolumn{2}{|c|}{ Females } & \multicolumn{2}{|c|}{ Males } \\
\hline & $n$ & $r_{x y}$ & $n$ & $r_{x y}$ \\
\hline 1 & 2 & - & 2 & - \\
\hline 3 & 2 & - & 1 & - \\
\hline 6 & 10 & -0.005 & 4 & -0.016 \\
\hline 7 & 7 & 0.000 & 8 & 0.023 \\
\hline 8 & 14 & -0.008 & 6 & -0.027 \\
\hline 9 & 3 & 0.046 & 12 & 0.000 \\
\hline 10 & 6 & 0.095 & 7 & 0.037 \\
\hline 11 & 12 & -0.001 & 2 & - \\
\hline $12 \mathrm{a}$ & 2 & - & 3 & $0.196^{*}$ \\
\hline $12 b$ & 3 & 0.020 & 2 & - \\
\hline 13 & 4 & 0.026 & 4 & 0.072 \\
\hline 17 & 5 & -0.004 & 1 & - \\
\hline 18 & 3 & 0.016 & 6 & -0.051 \\
\hline 19 & 7 & 0.003 & 3 & 0.045 \\
\hline 20 & 1 & - & 8 & -0.031 \\
\hline 21 & 3 & 0.078 & 3 & 0.067 \\
\hline 22 & 3 & -0.013 & 3 & 0.072 \\
\hline 23 & 6 & -0.004 & 7 & 0.024 \\
\hline 24 & 6 & -0.057 & 3 & $0.179 *$ \\
\hline 25 & 6 & $0.043^{*}$ & 7 & 0.039 \\
\hline 27 & 3 & 0.009 & 2 & - \\
\hline 29 & 7 & $0.100 *$ & 6 & 0.045 \\
\hline 30 & 2 & - & 6 & 0.030 \\
\hline 31 & 4 & 0.011 & 4 & 0.007 \\
\hline 32 & 7 & 0.020 & 6 & -0.006 \\
\hline 33 & 10 & 0.024 & 10 & -0.020 \\
\hline 34 & 5 & -0.005 & 2 & - \\
\hline 35 & 9 & 0.012 & 10 & -0.015 \\
\hline Mean & & 0.018 & & 0.032 \\
\hline
\end{tabular}

Note: Mean relatedness estimates were only calculated if $n \geq 3$ individuals. The false discovery rate was used to evaluate $p$ values, and an asterisk indicates a significant value. For the male analysis, the experiment-wide alpha $\left(\alpha_{\mathrm{EW}}\right)$ was 0.014 . For the analysis that included only females, the $\alpha_{\mathrm{EW}}$ was 0.013 .

by chance (Table 2). Our spatial autocorrelation analysis revealed that levels of relatedness were significantly higher than expected within local populations (distance interval 1: $r_{x y}=0.006, p=0.001$ ), but not at any of the other distance intervals examined $(1-6,6-12,12-18$, 18-24, 24-30, $>30$ km; Fig. 1).

\section{Sex-biased dispersal}

We failed to detect any evidence of sex-biased natal dispersal using any of the four approaches that we undertook. First, while we observed slightly higher levels of mean relatedness among males within local populations than among females (Table 3), the numbers of patches that exhibited significantly higher levels of relatedness based on panmictic expectations did not differ between the sexes. Second, although the mean level of assignment (mAIc) was larger for females $(\mathrm{mAIc}=$ 0.04) than males (mAIc $=-0.05)$, the difference between these two values was not significantly different from random expectations. Third, the ratio of our sex-specific estimates of vAIc (males vAIc $=6.43$; females vAIc $=7.30$ ) was also not significantly different from random expectations. Finally, the difference in $F_{\mathrm{ST}}$ values for females (0.010) and males (0.009) was also not significantly different from random expectations. Thus, based on the four separate approaches, we found no evidence for sex-biased dispersal within our data set.

\section{Landscape-level genetic structure}

The results of all of the STRUCTURE and GENELAND analyses failed to reveal any evidence of significant genetic partitioning across the study area. For STRUCTURE, the highest mean estimate of the likelihood of the data occurred at $K=1$ (i.e., all individuals considered to be sampled from a single panmictic population) and we did not observe a sharp increase in $\Delta K$ at any higher values of $K$. For GENELAND, all 10 independent runs used to infer the number of populations indicated that $K=1$. Likewise, no evidence of isolation by distance was detected across our study landscape $(r=0.02, p=0.07)$.

\section{Discussion}

In this research, we observed a significant but low level of population genetic structure $\left(F_{\mathrm{ST}}=0.005\right)$ for opossums inhabiting a highly fragmented, agricultural ecosystem. Genetic differentiation among local population pairs was highly variable and mean relatedness within local opossum populations rarely exceeded random expectations. Our results are in sharp contrast to those for raccoons inhabiting this same landscape, which exhibit significant levels of genetic differentiation among local populations and a high degree of genetic relatedness within many local populations, possibly attributed to high levels of site fidelity (Dharmarajan et al. 2009). Indeed, mean relatedness values within local raccoon populations were significantly greater than random expectations in 52\% of local populations of raccoons (Dharmarajan et al. 2009), compared with $7 \%$ observed for local populations of Virginia opossums in this study. These data suggest that these two highly abundant, generalist mesopredators exhibit dramatically different ecological and behavioral attributes to thrive within the same landscape.

Another significant finding of this study was the lack of support for the occurrence of sex-biased natal dispersal in the opossum, despite a number of previous accounts indicating that this species exhibits male-biased natal dispersal (Fitch and Sandidge 1953; Holmes and Sanderson 1965; Wright 1989; Ryser 1995). Although natal dispersal serves various functions, it is thought to have evolved to reduce competition among kin and conspecifics, avoid inbreeding, and cope with habitat and environmental variability (Bowler and Benton 2005). For example, spatial variation in patch quality, population density, demographic structure, and resource availability all have been shown to influence individual and population-level dispersal patterns (Ims and Hjermann 2001; Wiens 2001). Previous studies documenting male-biased natal dispersal in Virginia opossums have evaluated relatively small study areas ( $\leq 3700 \mathrm{ha})$ characterized by large tracts of contiguous forest $(\geq 238$ ha) with limited 
agricultural land use (Fitch and Sandidge 1953; Holmes and Sanderson 1965; Wright 1989; Ryser 1995). Alternatively, the expansive $\left(1165 \mathrm{~km}^{2}\right)$, highly fragmented agricultural ecosystem in which our research was conducted is characterized by a high degree of complexity, with discrete forest patches embedded in a large agricultural matrix. The spatial and temporal variation in the distribution of resources in agriculturally fragmented landscapes likely favors natal dispersal of both sexes (Bowler and Benton 2005). However, dispersal of both sexes might also be favored to reduce local resource competition among closely related individuals, but this mechanism requires the direct identification of kin unless a fixed strategy within the species had evolved (Bowler and Benton 2005). Indeed, previous research indicates that young Virginia opossums can discriminate between mothers and unrelated females, but it is unknown how this would translate to interactions among independent adults (Holmes 1992). Furthermore, results from our research, combined with the results from the previously discussed studies, indicate the Virginia opossum has not evolved a fixed dispersal strategy across its range. Nevertheless, molecular approaches should be employed in ecosystems with limited agricultural land use to more closely examine patterns of sex-biased dispersal in this species.

Our analysis of landscape-level genetic structure in opossums did not detect any evidence of significant population structure at this spatial scale $(K=1)$. Also, analyses did not reveal any significant barriers to gene flow despite the presence of three rivers and two large reservoirs within the study area. Although rivers have been shown to be significant barriers to dispersal in both European badgers (Meles meles (L., 1758)) and raccoons (Cullingham et al. 2009; Frantz et al. 2010), Virginia opossums are effective swimmers (McManus 1974) and are known to readily use anthropogenic features (e.g., bridges) to traverse both rivers and reservoirs. In addition, the unique taxonomic and natural history characteristics of the Virginia opossum likely contribute to the absence of genetic structure at the landscape scale. For example, female Virginia opossums carry young in the pouch, enabling individuals to move more freely throughout the landscape than competing placental mammals (Hossler et al. 1994). Additionally, the total amount of parental care differs between the Virginia opossum and its primary competitor, the raccoon. The Virginia opossum invests approximately 120 days of parental care (Gardner and Sunquist 2003) compared with 189 days of parental investment typical of raccoons (Gehrt 2003; Schneider et al. 1971).

Generalist mesopredators are often cited as being insensitive to habitat fragmentation with respect to abundance owing to their mobility, flexible diet, and ability to use a diverse array of habitats (Crooks 2002; Saunders et al. 1991). Furthermore, while the apparent success of mesopredators in fragmented ecosystems often has been attributed to their ability to adapt to complex spatial and temporal distributions of both anthropogenic and natural resources, limited empirical data exist pertaining to fine-scale social and population structure in the context of these behavioral adaptations. In this research, we demonstrated that Virginia opossums in fragmented, agricultural ecosystem display little evidence of genetic structure at both the local and landscape scales. The lack of any genetic structure in this species in an agricultur- ally fragmented system may be attributed to its flexible diet, reduced amount of parental care, and the dispersal capabilities of both sexes.

\section{Acknowledgements}

We thank two anonymous reviewers for comments that greatly improved the manuscript. This work would not have been possible without the permission of numerous private landowners who graciously permitted us to trap on their land. We thank J.E. Fike for her assistance with laboratory protocols along with D. Poer and C. Walters. We also thank Z.H. Olson for his assistance in the field, as well as countless other technicians. Purdue University and the Department of Forestry and Natural Resources provided funding for this research.

\section{References}

Allen, C.H., Marchinton, R.L., and Lentz, W.M. 1985. Movement, habitat use and denning of opossums in the Georgia Piedmont. Am. Midl. Nat. 113(2): 408-412. doi:10.2307/2425591.

Beasley, J.C., Devault, T.L., and Rhodes, O.E., Jr. 2007. Home-range attributes of raccoons in a fragmented agricultural region of northern Indiana. J. Wildl. Manage. 71(3): 844-850. doi:10.2193/ 2006-022.

Beasley, J.C., Beatty, W.S., Olson, Z.H., and Rhodes, O.E., Jr. 2010. A genetic analysis of the Virginia opossum mating system: evidence of multiple paternity in a highly fragmented landscape. J. Hered. 101(3): 368-373. doi:10.1093/jhered/esp114. PMID: 19995804.

Beasley, J.C., Olson, Z.H., Dharmarajan, G., Eagan, T.S., II, and Rhodes, O.E., Jr. 2011. Spatio-temporal variation in the demographic attributes of a generalist mesopredator. Landsc. Ecol. 26(7): 937-950. doi:10.1007/s10980-011-9619-x.

Benjamini, Y., and Yekutieli, D. 2001. The control of the false discovery rate under dependency. Ann. Stat. 29(4): 1165-1188.

Bowler, D.E., and Benton, T.G. 2005. Causes and consequences of animal dispersal strategies: relating individual behavior to spatial dynamics. Biol. Rev. Camb. Philos. Soc. 80(2): 205-225. doi:10. 1017/S1464793104006645. PMID:15921049.

Bowman, J., Jaeger, J.A.G., and Fahrig, L. 2002. Natal dispersal distance of mammals is proportional to home range size. Ecology, 83(7): 2049-2055. doi:10.1890/0012-9658(2002)083[2049: DDOMIP]2.0.CO;2.

Crooks, K.R. 2002. Relative sensitivities of mammalian carnivores to habitat fragmentation. Conserv. Biol. 16(2): 488-502. doi:10. 1046/j.1523-1739.2002.00386.x.

Crooks, K.R., and Soulé, M.E. 1999. Mesopredator release and avifaunal extinctions in a fragmented system. Nature, 400(6744): 563-566. doi:10.1038/23028.

Csilléry, K., Johnson, T., Beraldi, D., Clutton-Brock, T., Coltman, D., Hansson, B., Spong, G., and Pemberton, J.M. 2006. Performance of marker-based relatedness estimators in natural populations of outbred vertebrates. Genetics, 173(4): 2091-2101. doi:10.1534/ genetics.106.057331. PMID:16783017.

Cullingham, C.I., Kyle, C.J., Pond, B.A., Rees, E.E., and White, B.N. 2009. Differential permeability of rivers to raccoon gene flow corresponds to rabies incidence in Ontario, Canada. Mol. Ecol. 18(1): 43-53. PMID:19140963.

Dallas, J.F., Marshall, F., Piertney, S.B., Bacon, P.J., and Racey, P.A. 2002. Spatially restricted gene flow and reduced microsatellite polymorphism in the Eurasian otter (Lutra lutra) in Britain. Conserv. Genet. 3(1): 15-29. doi:10.1023/A:1014259218632.

DeWoody, J.A., Bickham, J.W., Michler, C.H., Nichols, K.M., 
Rhodes, O.E., Jr., and Woeste, K.E. 2010. Molecular approaches to natural resource conservation. University of Cambridge Press, New York.

Dharmarajan, G., Beasley, J.C., Fike, J.A., and Rhodes, O.E., Jr. 2009. Population genetic structure of raccoons (Procyon lotor) inhabiting a highly fragmented landscape. Can. J. Zool. 87(9): 814-824. doi:10.1139/Z09-072.

Ebinger, J.E. 1997. Forest communities of the Midwestern United States. In Conservation in highly fragmented landscapes. Edited by M.W. Schwartz. Chapman and Hall, New York. pp. 3-23.

Evanno, G., Regnaut, S., and Goudet, J. 2005. Detecting the number of clusters of individuals using the software STRUCTURE: a simulation study. Mol. Ecol. 14(8): 2611-2620. doi:10.1111/j. 1365-294X.2005.02553.x. PMID:15969739.

Favre, L., Balloux, F., Goudet, J., and Perrin, N. 1997. Female-biased dispersal in the monogamous mammal Crocidura russula: evidence from field data and microsatellite patterns. Proc. R. Soc. Lond. B Biol. Sci. 264(1378): 127-132. doi:10.1098/rspb. 1997.0019.

Fike, J.A., Beasley, J.C., and Rhodes, O.E., Jr. 2009. Isolation of 21 polymorphic microsatellite markers for Virginia opossum (Didelphis virginiana). Mol. Ecol. Resour. 9(4): 1200-1202. doi:10. 1111/j.1755-0998.2009.02606.x. PMID:21564875.

Fitch, H.S., and Sandidge, L.L. 1953. Ecology of the opossum on a natural area in northeastern Kansas. Univ. Kans. Publ. Mus. Nat. Hist. 7: 305-338.

Frantz, A.C., Pope, L.C., Etherington, T.R., Wilson, G.J., and Burke, T. 2010. Using isolation-by-distance-based approaches to assess the barrier effect of linear landscape elements on badger (Meles meles) disperal. Mol. Ecol. 19(8): 1663-1674. doi:10.1111/j.1365294X.2010.04605.x. PMID:20345687.

Gardner, A.L., and Sunquist, M.E. 2003. Opossum. In Wild mammals of North America: biology, management, and conservation. Edited by G.A. Feldhamer, B.C. Thompson, and J.A. Chapman. Johns Hopkins University Press, Baltimore, Md. pp. 3-29.

Gehring, T.M., and Swihart, R.K. 2003. Body size, niche breadth, and ecologically scaled reponses to habitat fragmentation: mammalian predators in an agricultural landscape. Biol. Conserv. 109(2): 283-295. doi:10.1016/S0006-3207(02)00156-8.

Gehrt, S.D. 2003. Raccoon. In Wild Mammals of North America: biology, management, and conservation. Edited by G.A. Feldhamer, B.C. Thompson, and J.A. Chapman. Johns Hopkins University Press, Baltimore, Md. pp. 611-634.

Gillette, L.N. 1980. Movement patterns of radio-tagged opossums in Wisconsin. Am. Midl. Nat. 104(1): 1-12. doi:10.2307/2424953.

Gipson, P.S., and Kamler, J.F. 2001. Survival and home ranges of opossums in northeastern Kansas. Southwest. Nat. 46(2): 178182. doi: $10.2307 / 3672526$.

Goudet, J. 1995. FSTAT (version 1.2): a computer program to calculate $F$-statistics. J. Hered. 86(6): 485-486.

Goudet, J. 2002. FSTAT: a computer program to calculate $F$ statistics. Version 2.9.3 [computer program]. Available from http:// www2.unil.ch/popgen/softwares/fstat.htm [accessed 11 August 2009].

Goudet, J., Raymond, M., de Meeüs, T., and Rousset, F. 1996. Testing differentiation in diploid populations. Genetics, 144(4): 1933-1940. PMID:8978076.

Guillot, G., Estoup, A., Mortier, F., and Cosson, J. 2005a. A spatial statistical model for landscape genetics. Genetics, 170(3): 12611280. doi:10.1534/genetics.104.033803. PMID:15520263.

Guillot, G., Mortier, F., and Estoup, A. 2005b. GENELAND: a computer package for landscape genetics. Mol. Ecol. Notes, 5(3): 712-715. doi:10.1111/j.1471-8286.2005.01031.x.
Hardy, O.J., and Vekemans, X. 2002. SPAGeDi: a versatile computer program to analyse spatial genetic structure at the individual or population levels. Mol. Ecol. Notes, 2(4): 618-620. doi:10.1046/j. 1471-8286.2002.00305.x.

Holmes, D.J. 1992. Odors as cues for orientation to mothers by weanling Virginia opossums. J. Chem. Ecol. 18(12): 2251-2259. doi:10.1007/BF00984948.

Holmes, A.C.V., and Sanderson, G. 1965. Populations and movements of opossums in east-central Illinois. J. Wildl. Manage. 29(2): 287-295. doi:10.2307/3798433.

Hossler, R.J., McAninch, J.B., and Harder, J.D. 1994. Maternal denning behavior and survival juveniles in opossums in southeastern New York. J. Mammal. 75(1): 60-70. doi:10.2307/ 1382236.

Ims, R., and Hjermann, D. 2001. Condition-dependent dispersal. In Dispersal. Edited by J. Clobert, E. Danchin, A.A. Dhondt, and J.D. Nichols. Oxford University Press, New York.

Kanda, L.L., Fuller, T.K., and Sievert, P.R. 2006. Landscape associations of road-killed Virginia opossums (Didelphis virginiana) in central Massachusetts. Am. Midl. Nat. 156(1): 128-134. doi:10.1674/0003-0031(2006)156[128:LAORVO]2.0.CO;2.

Keyghobadi, N. 2007. The genetic implications of habitat fragmentation for animals. Can. J. Zool. 85(10): 1049-1064. doi:10.1139/ Z07-095.

Latch, E.K., Scognamillo, D.G., Fike, J.A., Chamberlain, M.J., and Rhodes, O.E., Jr. 2008. Deciphering ecological barriers to North American river otter (Lontra canadensis) gene flow in the Louisiana landscape. J. Hered. 99(3): 265-274. doi:10.1093/ jhered/esn009. PMID:18316322.

Lewis, P.O., and Zaykin, D. 2001. Genetic data analysis (GDA): computer program for the analysis of allelic data. Version 1.1 [computer program]. Available from http://www.eeb.uconn.edu/ people/plewis/software.php [accessed 10 August 2009].

Mantel, N. 1967. The detection of disease clustering and a generalized regression approach. Cancer Res. 27(2): 209-220. PMID:6018555.

McManus, J.J. 1974. Didelphis virginiana. Mamm. Species No. 40: 1-6. doi:10.2307/3503783.

Miller, M.P. 2005. Alleles In Space (AIS): computer software for the joint analysis of inter-individual spatial and genetic information. J. Hered. 96(6): 722-724. doi:10.1093/jhered/esi119. PMID: 16251514.

Moore, J.E., and Swihart, R.K. 2005. Modeling patch occupancy by forest rodents: incorporating detectability and spatial autocorrelation with hierarchically structured data. J. Wildl. Manage. 69(3): 933-949. doi:10.2193/0022-541X(2005)069[0933:MPOBFR]2.0. $\mathrm{CO} ; 2$.

Narum, S.R. 2006. Beyond Bonferroni: less conservation analyses for conservation genetics. Conserv. Genet. 7(5): 783-787. doi:10. 1007/s10592-005-9056-y.

Nei, M., Tajima, F., and Tateno, Y. 1983. Accuracy of estimated phylogenetic trees from molecular data. II. Gene frequency data. J. Mol. Evol. 19(2): 153-170. doi:10.1007/BF02300753.

Peakall, R., and Smouse, P.E. 2006. GENALEX 6: genetic analysis in Excel. Population genetic software for teaching and research. Mol. Ecol. Notes, 6(1): 288-295. doi:10.1111/j.1471-8286.2005.01155. $\mathrm{x}$.

Pritchard, J.K., Stephens, M., and Donnelly, P. 2000. Inference of population structure using multilocus genotype data. Genetics, 155(2): 945-959. PMID:10835412.

Queller, D.C., and Goodnight, K.F. 1989. Estimating relatedness using genetic markers. Evolution, 43(2): 258-275. doi:10.2307/ 2409206.

Ryser, J. 1995. Activity, movement, and home range of the Virginia 
opossum (Didelphis virginiana) in Florida. Bull. Fla. Mus. Nat. Hist. 6: 177-194.

Sacks, B.N., Statham, M.J., Perrine, J.D., Wisely, S.M., and Aubry, K.B. 2010. North American montane fed foxes: expansion, fragmentation, and the origin of the Sacramento Valley red fox. Conserv. Genet. 11(4): 1523-1539. doi:10.1007/s10592-0100053-4.

Saunders, D.A., Hobbs, R.J., and Margules, C.R. 1991. Biological consequences of ecosystem fragmentation: a review. Conserv. Biol. 5(1): 18-32. doi:10.1111/j.1523-1739.1991.tb00384.x.

Schneider, D.E., Mech, L.D., and Tester, J.R. 1971. Movements of female raccoons and their young as determined by radio-tracking. Anim. Behav. Monogr. 4(1): 1-43.

Schneider, S., Roessli, D., and Excoffier, L. 2000. ARLEQUIN: a software for population genetics data analysis. Version 2.0 [computer program]. Available from http://www.cmpg.iee.unibe. ch/content/softwares__services/computer_programs/arlequin/ index_eng.html [accessed 10 August 2009].

Weir, B.S., and Cockerham, C.C. 1984. Estimating $F$-statistics for the analysis of population structure. Evolution, 38(6): 1358-1370. doi:10.2307/2408641.

Whitaker, J.O., and Mumford, R.E. 2009. Mammals of Indiana. Indiana University Press, Bloomington.

Wiens, J.A. 2001. The landscape context of dispersal. In Dispersal. Edited by J. Clobert, E. Danchin, A.A. Dhondt, and J.D. Nichols. Oxford University Press, New York.

Wright, D.D. 1989. Mortality and natal dispersal of juvenile opossums, Didelphis virginiana. M.Sc. thesis, University of Florida, Gainesville. 